\title{
Pengaruh Pendidikan Kesehatan Senam Nifas Terhadap Pengetahuan Primipara Tentang Senam Nifas di Wilayah Kerja Puskesmas Lubuk Buaya Padang
}

\author{
Febri Wendari ${ }^{\text {a }}$, Vetty Priscilla ${ }^{a}$, Wedya Wahyu ${ }^{\text {a }}$ \\ ${ }^{a}$ Fakultas Keperawatan Universitas Andalas \\ Korespendensi : whe-niekrissy \\ E-mail:whe_niekrissy@yahoo.co.id
}

\begin{abstract}
Puerperal is an important activity done after childbirth, one of the goals to prevent complications at a time puerperal. To increase the knowledge of mothers after childbirth mainly primipara about puerperal exercise is through health education. The aim of the research is to know the effect of puerperal exercise health education on primipara knowledge about puerperal exercise in lubuk buaya health center padang 2013. This research uses a quasi-experimental approach to pre-posttest design, with a sample of 19 primipara. Retrieval of data started from February 23 to March 22, with sampling purposive sampling using questionnaire. Analizyng the data is using Wilcoxon. The result showed that the primipara that have a good knowledge of as much(10,5\%)before being given the health education, after given a puerperal exercise healt education, primipara that have a knowledge of good as much (84,2\%). The result of statistical test showed the influence of puerperal execercise health education of knowledge $(p=0,000)$. Advice to the clinic to be able to make a puerperal exercise routine program of restoring the health of mothers after childbirth.
\end{abstract}

Key words: Puerperal puerperal, Health education, Primipara

\begin{abstract}
Abstrak: Senam nifas merupakan kegiatan yang sangat penting dilakukan setelah persalinan, Salah satu tujuannya untuk mencegah komplikasi pada waktu nifas. Untuk meningkatkan pengetahuan ibu setelah persalinan terutama primipara tentang senam nifas adalah melalui pendidikan kesehatan. Tujuan penelitian ini untuk mengetahui pengaruh pendidikan kesehatan senam nifas terhadap pengetahuan primipara tentang senam nifas di wilayah kerja Puskesmas Lubuk buaya padang tahun 2013. Jenis penelitian ini menggunakan quasi eksperimen dengan pendekatan pre-posttest design, dengan jumlah sampel 19 orang primipara. Pengambilan data dimulai dari 23 Februari sampai 22 Maret dengan pengambilan sampel secara purposive sampling dengan menggunakan instrument kuosioner.Analisa data menggunakan wilcoxon. Hasil penelitian didapatkan bahwa primipara yang mempunyai pengetahuan baik sebanyak (10,5\%) sebelum diberikan pendidikan kesehatan, setelah diberikan pendidikan kesehatan senam nifas primipara yang mempunyai pengetahuan baik sebanyak $(84,2 \%)$, hasil uji statistik menunjukkan adanya pengaruh pendidikan kesehatan senam nifas terhadap pengetahuan $(\mathrm{p}=0,000)$. Saran bagi puskesmas untuk dapat menjadikan senam nifas sebagai program rutin sebagai upaya pemulihan kesehatan ibu pasca persalinan.
\end{abstract}

Kata kunci: Senam nifas, Pendidikan kesehatan, Primipara

\section{PENDAHULUAN}

Masa nifas (puerperium) adalah masa enam minggu sejak bayi lahir sampai organ-organ reproduksi kembali ke keadaan normal seperti sebelum hamil (Bobak, 2005). Umumnya ibu merasa sangat lelah setelah melahirkan, apalagi proses persalinannya berlangsung cukup lama. Dahulu ibu harus cukup beristirahat, harus tidur telentang selama kurang lebih 8 jam setelah bersalin. Setelah itu baru boleh miring kiri dan miring kanan untuk mencegah terjadinya risiko timbunan plak di pembuluh darah (trombosis dan tromboemboli) akibat terlalu lama tidak bergerak. Namun sekarang setelah melahirkan ibu dianjurkan untuk mobilisasi dini (early moblitation) secara aktif secepat mungkin jika sudah memungkinkan setelah persalinan (Jones 2001).

Berdasarkan hasil hasil survey demografi dan kesehatan Indonesia angka kematian ibu di Indonesia masih sangat 
tinggi dibandingkan negara Asean lainnya, angka kematian ibu (AKI) 228 per 100.000 kelahiran hidup. Berdasarkan kesempatan global ( Millenium Development Goal's) pada tahun 2015 diharapkan angka kematian ibu (AKI) menurun sebesar tigaperempatnya dalam kurun waktu 19902015, perdarahan menempati persentasi tertinggi penyebab kematian ibu (28 persen). Lebih dari $60 \%$ kematian ibu terjadi saat persalinan dan lebih dari $50 \%$ terjadi sehari setelah persalinan (Depkes, 2011).

Perdarahan post partum dapat terjadi akibat kegagalan miometrium untuk berkontraksi setelah persalinan sehingga uterus dalam keadaan relaksasi penuh, kurang baik dan lembek. Salah satu cara agar kontraksi otot- otot uterus tetap baik sampai akhir nifas yaitu dengan mobilisasi dini dan gerakan sederhana seperti senam nifas. Karena senam nifas latihan peregangan otot-otot yang dilakukan setelah persalinan (Bobak, 2005).

Saat melaksanakan senam nifas terjadi kontraksi otot-otot perut yang juga membantu proses involusi. Pada masa nifas, alat-alat genetalia akan berangsurangsur pulih kembali ke keadaan sebelum hamil. Bentuk tubuh akan menjadi baik, otot dasar panggul menjadi kuat sehinngga stress inkontinensia dapat di cegah, dam membantu memperbaiki sirkulasi darah di seluruh tubuh (Farrer, 2001). Senam nifas sebaiknya dilakukan 24 jam setelah ibu melahirkan (Yuliarti, 2010). Pada pasien caesar ambulasi dini dan latihan senam nifas dilakukan 24-36 jam setelah melahirkan (Farrer, 2001).

Senam ini harus dilakukan sesering mungkin setelah persalinan (Brayshaw, 2007). Senam nifas ini bertujuan untuk mempertahankan dan meningkatkan sirkulasi ibu, mencegah komplikasi yang timbul pada waktu nifas (tromboflebitis), mempercepat involusi, dan mengencangkan otot perut dan perineum, memperbaiki sikap tubuh setelah hamil dan melahirkan, dan mencegah timbulnya varises (Saminem, 2006).
Senam nifas memang jarang dilakukan oleh ibu yang telah melakukan persalinan. Ada tiga alasan kenapa ibu tidak melakukan senam nifas, diantaranya karena memang tidak tahu cara melakukan senam nifas, rasa sakit dan kelelahan yang dirasakan ibu setelah melahirkan, terlalu bahagia dengan kehadiran bayi. Senam nifas sangatlah mudah, Ibu tidak harus melakukan gerakan yang macam-macam pascamelahirkan, hanya duduk dan bersila. Bila ibu merasa sakit, senam nifas bisa dilakukan sambil tidur (Yuliarti, 2010).

Salah satu cara untuk meningkatkan pengetahuan dan perilaku seseorang adalah dengan memberikan pendidikan kesehatan. Agar masyarakat dapat berprilaku kesehatan dengan baik maka perlu informasi. Dengan memberikan informasi akan meningkat sehingga akan timbul kesadaran pada individu atau masyarakat untuk berprilaku sesuai dengan pengetahuan yang dimilikinya. Pendidikan kesehatan merupakan suatu upaya untuk mempengaruhi orang lain baik individu, kelompok atau masyarakat. Untuk meningkatkan pengetahuan, sikap, dan praktek masyarakat dalam memelihara dan meningkatkan kesehatan mereka sendiri (Notoadmojo, 2003).

Pendidikan kesehatan penting diberikan pada semua ibu nifas, tetapi pada primipara lebih penting karena primipara adalah seorang wanita yang melahirkan bayi hidup untuk pertama kalinya (Mochtar,1999). Melahirkan merupakan pengalaman yang baru baginya dan seringkali kurang pengetahuan dalam perawatan diri. Petugas kesehatan perlu memberikan pendidikan kesehatan tentang perawatan diri pada masa nifas setelah persalinan, salah satunya latihan senam nifas. Pendidikan kesehatan senam nifas diberikan pada hari kedua dan ketiga setelah ibu pulang kerumah (Bobak, 2005).

Pelaksanaan senam nifas dan program senam nifas serta Poster-poster dan informasi tentang senam nifas belum ada di Puskesmas Lubuk Buaya. Petugas kesehatan disana juga belum pernah 
memberikan penyuluhan tentang senam nifas.

Setelah dilakukan studi pendahuluan pada bulan februari 2013 pada 7 orang ibu yang ditemui dirumah di wilayah kerja Puskesmas Lubuk Buaya 1 orang pernah mendengar tetapi tidak pernah melakukan senam nifas, dan 6 orang ibu belum pernah mendengar tentang senam nifas. Ibu juga takut bergerak setelah persalinan dan lebih banyak tidur dengan alasan masih lelah, nyeri dan takut terjadi perdarahan. Kerugian apabila ibu tidak melakukan latihan senam nifas dapat terjadi infeksi karena involusi uterus yang kurang baik sehingga sisa darah tidak dapat dikeluarkan, perdarahan abnormal, thrombosis vena dan dapat terjadi varises.

Oleh sebab itu peneliti merumuskan masalah penelitian apakah ada pengaruh pendidikan kesehatan senam nifas terhadap pengetahuan primipara tentang senam nifas senam nifas di wilyah kerja Puskesmas Lubuk Buaya Padang tahun 2013.

Tujuan penelitian ini diketahuinya pengaruh pendidikan kesehatan senan nifas terhadap pengetahuan primipara tentang senam nifas di wilayah kerja Puskesmas Lubuk Buaya Padang tahun 2013.

\section{Manfaat:}

\section{Bagi Profesi Keperawatan}

Diharapkan penelitian ini dapat memeberikan masukan bagi profesi dalam mengembangkan perencanaan keperwatan maternitas yang akan dilakukan tentang pengaruh pendidikan kesehatan senam nifas terhadap pengetahuan primipara tentang senam nifas.

\section{Bagi Peneliti}

Untuk menambah wawasan dan pengetahuan dan menerapkan ilmu pengetahuan yang didapatkan penulis selama dibangku kuliah.
3. Bagi Institusi Pendidikan

Peneliti menjadikan penelitian ini sebagai acuan pembuatan karya tulis ilmiah yang lebih baik dimasa yang akan datang dan untuk peneliti selanjutnya agar dapat melakukan penelitian lebih lanjut dengan variabel yang berbeda.

\section{METODE}

Penelitian ini menggunakan desain quasi-eksperiment tanpa kelompok kontrol dengan pendekatan one group pretestposttest (Nursalam, 2008). Yaitu kelompok subjek ( primipara) sebelumnya dilakukan pengukuran pengetahuan (pre test) kepada primipara. Kemudian diberikan perlakuan yaitu pendidikan kesehatan Senam nifas (X). Kemudian baru di lakukan pengukuran pengetahuan tentang senam nifas (posttest). Pendidikan kesehatan diberikan pada hari ketiga setelah persalinan pada semua para, posttest dilakukan dua minggu setelah pretest. Responden adalah primipara pada fase Taking Hold yang berada diwilayah kerja Puskesmas Lubuk Buaya Padang Tahun 2013.

\section{HASIL DAN PEMBAHASAN}

Pengambilan data penelitian ini dilakukan di wilayah kerja puskesmas Lubuk Buaya Padang dari tanggal 23 Maret sampai 22 April 2013. Jumlah responden pada penelitian ini tidak sesuai dengan rencana penelitian sebelumnya yaitu awalnya sampel berjumlah 20 orang menjadi 19 orang yang memenuhi kriteria sampel untuk dijadikan sebagai responden dan 1 orang lagi tidak memenuhi kriteria sampel karena drop out selama penelitian dimana responden tidak ada pada saat posttest

\section{A. Analisa Univariat}

Gambaran karakteristik responden di wilayah kerja Puskesmas Lubuk Buaya Padang Tahun 2013 dalam penelitian ini meliputi: umur, pendidikan pekerjaan dan pengetahuan. 
Tabel 5.1. Distribusi Frekuensi Pengetahuan Primipara Berdasarkan Umur, Pendidikan dan Pekerjaan di Wilayah Kerja Puskesmas Lubuk Buaya Padang Tahun 2013.

\begin{tabular}{|c|c|c|}
\hline \multicolumn{1}{|c|}{ Karakteristik } & Frekuensi & Persentase \\
\hline \begin{tabular}{|l} 
1. Umur \\
a. 12-20 Tahun (Masa remaja)
\end{tabular} & 1 & 5,3 \\
b. >20-30 Tahun (Dewasa awal) & 18 & 94,7 \\
\hline Total & 19 & 100 \\
\hline 2. Pendidikan & 4 & \\
a. SLTP & 10 & 21,1 \\
b. SMA & 5 & 52,6 \\
c. Perguruan Tinggi & 19 & 26,3 \\
\hline Total & & 100 \\
\hline 3. Pekerjaan & 12 & 36,8 \\
a. Bekerja & 19 & 63,2 \\
b. Tidak bekerja & & 100 \\
\hline Total
\end{tabular}

Dari tabel 5.1 dapat dilihat bahwa hampir semua responden $(94,7)$ berada pada rentang usia dewasa, dilihat dari pendidikan lebih dari setengah responden tamatan SLTA sebanyak $52,6 \%$ dan dilihat dari pekerjaan lebih dari setengah responden $63,2 \%$ tidak bekerja

Tabel 5.2. Distribusi Frekuensi Responden Berdasarkan Pengetahuan Sebelum dan Sesudah Diberikan Pendidikan Kesehatan Senam Nifas di Wilayah Kerja Puskesmas Lubuk buaya Padang Tahun 2013

\begin{tabular}{|c|l|c|c|c|c|c|c|}
\hline \multirow{2}{*}{ NO } & \multirow{2}{*}{ Pengetahuan } & \multicolumn{2}{|c|}{ Baik } & \multicolumn{2}{c|}{ Kurang baik } & \multicolumn{2}{c|}{ Total } \\
\cline { 3 - 8 } & & $\mathrm{f}$ & $\%$ & $\mathrm{f}$ & $\%$ & $\mathrm{f}$ & $\%$ \\
\hline 1. & Sebelum & 2 & 10,5 & 17 & 89,5 & 19 & 100 \\
\hline 2. & Sesudah & 16 & 84,2 & 3 & 15,8 & 19 & 100 \\
\hline
\end{tabular}

Pada tabel 5.2 di atas menunjukan bahwa primipara yang mempuyai pengetahuan baik sebanyak $(10,5 \%)$ sebelum diberikan pendidikan kesehatan. Setelah di berikan pendidikan kesehatan tentang senam nifas primipara yang mempunyai pengetahuan baik sebanyak $(84,2 \%)$.

\section{B. Analisa Bivariat}

Analisa bivariat dalam penelitian ini berguna untuk melihat sejauh mana variable independen mempengaruhi variable dependen.

Tabel 5.3. Pengaruh Pendidikan kesehatan Senam Nifas Terhadap Pengetahuan PrimiparaTentang Senam Nifas di Wilayah Kerja Puskesmas Lubuk Buaya Padang Tahun 2013. 


\begin{tabular}{|c|l|c|c|c|c|}
\hline Variabel & & $\mathrm{N}$ & Mean Rank & $\mathrm{Z}$ & $\mathrm{P}$ \\
\hline \multirow{2}{*}{$\begin{array}{c}\text { Pengetahuan } \\
\text { Primipara Pada } \\
\text { Pretest-Postest }\end{array}$} & Negative Ranks & 0 &, 00 & \multirow{3}{*}{$-3,742$} & \multirow{3}{*}{0,000} \\
\cline { 2 - 5 } & Positive Ranks & 14 & 7,50 & \\
\cline { 2 - 5 } & Ties & 5 & & & \\
\cline { 2 - 5 } & Total & 19 & & & \\
\hline
\end{tabular}

Dari tabel diatas dapat dilihat bahwa 14 primipara mengalami positive ranks, yaitu terdapat $14 \mathrm{ibu}$ mengalami peningkatan pengetahuan tentang senam nifas. Hasil uji statistik didapatkan nilai $Z-3,742$ dan $p=0,000(p<0,05)$, maka dapat disimpulkan terdapat pengaruh yang bermakna pada pemberian pendidikan kesehatan senam nifas terhadap pengetahuan primipara tentang senam nifas di wilayah kerja Puskesmas Lubuk Buaya Padang tahun 2013.

A. Pengetahuan Primipara Sebelum dan Sesudah Pendidikan Kesehatan Senam Nifas di Wilayah kerja Puskesmas Lubuk Buaya Padang Tahun 2013

Berdasarkan hasil penelitian yang telah dilakukan didapatkan bahwa primipara yang mempunyai pengetahuan baik sebanyak $(10,5 \%)$ sebelum diberikan pendidikan kesehatan, setelah diberikan pendidikan kesehatan senam nifas primipara yang mempunyai pengetahuan baik sebanyak (84,2\%). Dari hasil penelitian ini tampak bahwa terjadi perubahan pengetahuan responden sebelum dan sesudah di berikan pendidkan kesehatan. Hal ini berarti salah satu upaya untuk meningkatkan pengetahuan responden, khususnya tentang senam nifas adalah dengan memberikan pendidikan kesehatan. Hasil penelitian Vivi (2013) juga menunjukan bahwa ada perbedaan pengetahuan pada kelompok yang tidak diberikan intervensi dengan yang diberikan intervensi pendidikan kesehatan rentang gerak sendi aktif post operasi orif pada pasien fraktur ekstremitas.

Salah satu faktor yang dapat mempengaruhi pengetahuan seseorang setelah diberikan pendidikan kesehatan senam nifas adalah pendidikan. Hasil penelitian diatas juga didukung oleh tingkat pendidikan responden, dimana 4 responden $(21,1 \%)$ tamat sekolah menengah pertama, 10 responden $(52,6 \%)$ tamat sekolah menengah atas dan 5 responden $(26,3 \%)$ tamat perguruan tinggi. Hal ini sesuai dengan pendapat Maulana (2009) dalam Titi (2011), bahwa tingkat pengetahuan seseorang dipengaruhi oleh pendidikan, dimana semakin tinggi tingkat pendidikan seseorang maka akan semakin tinggi pengetahuan yang dimiliki, karena seseorang yang tingkat pendidikannya lebih tinggi akan lebih mudah menerima dan memahami informasi yang diberikan. Selain itu juga karena adanya perhatian dan kesadaran dari responden untuk mendengarkan informasi yang diberikan oleh peneliti.

Faktor lain yang dapat mempengaruhi pengetahuan seseorang setelah diberikan pendidikan kesehatan adalah usia. Di lihat dari usia hampir semua responden $(94,7 \%)$ berada pada rentang usia dewasa. Singgih (1998) mengemukakan bahwa makin tua umur seseorang maka proses-proses perkembangan mentalnya bertambah baik, selain itu Ahmadi (2001) juga mengemukakan bahwa memang daya ingat seseorang itu salah satunya dipengaruhi oleh usia. Menurut peneliti, bertambahnya umur akan berpengaruh pada pertambahan pengetahuan yang diperoleh seseorang, Usia mempengaruhi terhadap daya tangkap dan pola pikir seseorang. Semakin bertambah usia akan semakin berkembang pula daya tangkap dan pola pikirnya, semakin banyak informasi yang dijumpai dan semakin banyak hal yang dikerjakan sehingga pengetahuan yang diperolehnya 
juga akan bertambah, dan hal itu tentunya juga didukung dengan tingkat pendidikan.

Berdasarkan hasil penelitian juga dapat dilihat Lebih dari separoh responden $(63,2 \%)$ tidak bekerja yang setiap harinya lebih banyak dirumah sehingga lebih sering terpapar dengan informasi, yang bisa didapatkan responden dari menonton televisi maupun dari membaca majalah atau buku, hal ini tidak sesuai dengan pendapat Notoadmojo (2007) bahwa pengetahuan juga dapat dipengaruhi oleh faktor eksternal seperti keterpaparan informasi, sosial budaya, keyakinan dan lingkungan, karena nilai terendah didapat pada primipara yang tidak bekerja.

Pengetahuan merupakan hasil dari tahu, dan ini terjadi setelah orang melakukan penginderaan terhadap suatu objek tertentu (Sunaryo, 2004). Meningkatnya pengetahuan responden juga dipengaruhi oleh faktor metode, media/alat peraga, dalam penelitian ini peneliti dalam memberikan pendidikan kesehatan senam nifas menggunakan metode pendidikan individual (perorangan). Dengan cara ini kontak antara responden dengan peneliti lebih intensif dan dasar digunakannya pendekatan individual ini karena setiap orang mempunyai masalah yang berbeda, sehingga dengan adanya kontak secara individu maka setiap masalah klien dapat diteliti dan lebih mudah melakukan pembinaan sebuah perilaku baru.

B. Pengaruh Pendidikan Kesehatan Senam Nifas terhadap Pengatahuan Primipara Tentang Senam Nifas di Wliyah Kerja Puskesmas Lubuk Buaya Padang Tahun 2013

Berdasarkan hasil penelitian dengan uji Non Parametric yang digunakan Wilcoxon di dapatkan bahwa 14 primipara mengalami positive ranks yaitu peningkatan pengetahuan tentang senam nifas. Hasil uji statistik didapat nilai $\mathrm{p}=0,000 \quad(\mathrm{p}<0,05)$, ini artinya terdapat pengaruh yang bermakna antara pendidikan kesehatan terhadap pengetahuan primipara tentang senam nifas. Hal ini sesuai dengan penelitian yang dilakukan oleh Aiysah (2010) tentang pengaruh pemberian paket pendidikan kesehatan perawatan ibu nifas yang dimodifikasi terhadap pengetahuan, sikap dan perilaku ibu post partum primipara dalam merawat diri di Palembang, dimana dari hasil penelitian didapatkan bahwa ada pengaruh pendidikan kesehatan terhadap pengetahuan primipara. Perubahan pengetahuan dapat terjadi karena primipara telah mendapatkan pendidikan kesehatan senam nifas, sehingga wawasan dan pengetahuan primipara menjadi betambah tentang senam nifas. Hal ini sesuai dengan pendapat purwanto (2001), pengetahuan diperoleh melalui pengalaman,latihan dan proses belajar.

Meningkatnya pengetahuan responden juga dipengaruhi oleh faktorfaktor media dari edukasi personal, dimana dalam memberikan pendidikan kesehatan secara individual peneliti menggunakan lembar balik yang dapat menarik perhatian responden karena dapat menampilkan warna beserta gambar. Dalam hal ini peneliti juga memberikan leaflet untuk responden yang bisa dibaca sebagai penambah wawasan. Notoadmodjo (2005) mengatakan media yang baik berfungsi untuk membantu dalam proses pendidikan suatu pengajaran sehingga pesan kesehatan dapat disampaikan dengan jelas dan tepat. Selain hal tersebut pemberian pendidikan kesehatan pada primipara harus memperhatikan waktu dan juga kondidi fisik dan emosional primipara, sehingga primipara dapat menerima pendidikan kesehatan yang diberikan oleh peneliti.

Bobak (2005) mengatakan bahwa ibu pada fase taking hold, yang terjadi antara hari kedua dan ketiga post partum merupakan saat yang tepat untuk memberikan informasi tentang perawatan diri yaitu senam nifas. Pendidikan kesehatan senam nifas diberikan oleh peneliti pada hari ketiga post partum pada semua primipara, dimana primipara telah 
siap menerima materi yang diberikan. Responden penelitian ini adalah primipara yang mempunyai motivasi cukup kuat untuk belajar,dengan keinginan yang kuat ini dapat mempengaruhi hasil belajar yang baik. Penelitian ini menunjukan adanya perubahan pengetahuan sebelum dan sesudah diberikan pendidikan kesehatan. Berdasarkan pendapat diatas, maka peneliti berpendapat bahwa pendidikan kesehatan merupakan salah satu cara yang efektif digunakan untuk meningkatkan pengetahuan primipara tentang senam nifas.

\section{KESIMPULAN DAN SARAN}

Berdasarkan hasil penelitian yang dilakukan tentang pengaruh pendidikan kesehatan senam nifas terhadap primipara tentang senam nifas diwilayah kerja Puskesmas Lubuk Buaya Padang tahun 2013:

1. Didapat primipara yang mempunyai pengetahuan baik sebanyak $(10,5 \%)$ sebelum diberikan pendidikan kesehatan senam nifas, setelah diberikan pendidikan kesehatan senam nifas primipara yang mempunyai pengetahuan baik sebanyak $(84,2 \%)$.

2. Terdapat pengaruh pendidikan kesehatan senam nifas terhadap perubahan pengetahuan primipara tentang senam nifas dengan nilai $\mathrm{p}=0,000(\mathrm{p}<0,05)$.

Berdasarkan penelitian yang telah penulis lakukan, disarankan :

1. Bagi Puskesmas Lubuk Buaya untuk dapat menerapkan pendidikan kesehatan senam nifas dalam rangka meningkatkan asuhan pelayanan keperawatan, dan menjadikan senam nifas sebagai program rutin sebagai upaya pemulihan kesehatan ibu setelah melahirkan.

2. Bagi institusi pendidikan dapat dijadikan sebagai informasi atau bahan masukan untuk pengembangan ilmu pengetahuan, khususnya tentang pengaruh pendidikan kesehatan terhadap pengetahuan senam nifas.

\section{DAFTAR PUSTAKA}

Alimul, A. (2012). Riset keperawatan \& teknik penulisan ilmiah (Edisi 2). Jakarta: Salemba Medika.

Arikunto, S. (2006). Prosedur penelitian suatu pendekatan praktik. Jakarta: Rineka cipta.

Aisyah. (2010). Tentang pengaruh pemberian paket pendidikan kesehatan perawatan ibu nifas yang dimodifikasi terhadap pengetahuan, sikap dan perilaku ibu post partum primipara dalam merawat diri di Palembang.

Bastable, S. B. (2002). Perawat sebagai pendidik: prinsip-prinsip pengajaran dan pembelajaran. Jakarta: EGC

Bobak. (2005). Keperawatan maternitas (Edisi 4). Jakarta: EGC

Brayshaw, E.(2007). Senam hamil \& nifas. Jakarta: EGC

Chomaria, N. (2012). Olahraga bagi ibu hamil dan menyusui. Jakarta: Gramedia

Dahlan, S. (2009). Statistik untuk kedokteran dan Kesehatan. Jakarta: Salemba Medika

Dinas kesehatan kota padang. (2012) Laporan tahunan dinas kesehatan kota padang.

Farrer, H. (2001). Keperawatan maternitas. Jakarta: EGC

Jones \& Llewellyn, Derek. (2002). Dasardasar obstetri dan ginekologi (Edisi.6). Jakarta: Hipokrates

Ko, Yi-Li dkk. (2008). Effects of postpartum exercise program on fatigue and depression during "doing-the-month" period. Diakses tanggal 28 Januari 2013 dari http://pic.518.com.tw/file/

Lusa. (2012). Tindak lanjut asuhan nifas di rumah. Diakses tanggal 3 Maret 2013. http://www.lusa.web.id/program- 
$\underline{\text { tindak-lanjut-asuhan-nifas-di- }}$

rumah/

Maulana, H. (2009). Promosi kesehatan (Cetakan I). Jakarta: EGC.

Mubarak. (2006). Buku ajar ilmu keperawatan komuntas 2. Jakarta: CV Sagung Seto

Notoatmodjo, S. ( 2003). Pendidikan kesehatan dan ilmu perilaku. Rineka Cipta: Jakarta

Notoatmodjo, S. (2005). Metodologi penelitian kesehatan. Jakarta: PT Rineka Cipta.

(2007). Pendidikan kesehatan dan ilmu perilaku. Rineka Cipta: Jakarta. (2010). Promosi kesehatan teori \& aplikasi. Jakarta: PT. Rineka Cipta Nursalam (2008). Konsep dan penerapan metodologi penelitian ilmu keperawatan pedoman skripsi, tesis, dan instrumen penelitian keperawatan. Jakarta : Salemba Medika.

Purwanto, N. (2001). Psikologi pendidikan. Bandung: Remaja Rosdakarya.

RSIA Nun. (2013). Senam nifas. Diakses tanggal 28 januari 2013 http://www.nun.co.id/pelayanan/s enam-nifas

Saminem. (2009). Kehamilan normal: seri asuhan kebidanan. Jakarta: EGC.

Sulistyawati, A. (2009). Buku ajar asuhan kebidanan pada ibu nifas. Yogyakarta: CV Andi Offset.

Sugiyono. (2010). Metode penelitian kuantitatif, kualitatif dan $R \& B$. Bandung: Alfabeta.

Sunaryo. (2004). Psikologi untuk keperawatan. Jakarta : EGC

Suliha, U (2002). Pendidikan kesehatan dalam keperawatan. Jakarta : EGC

Suparyanto. (2012). Apa itu masa nifas. Diakses tanggal 28 Januari 2013 http://www.carantrik.com/2012/11/ap a-itu-masa-nifas.html
Suparyanto. (2012) . Konsep dasar pengetahuan. Diakses tanggal 27 April 2013

http://amanahtp.wordpress.com/2011/

11/06/konsep-dasar-pengetahuan/

Titi. (2010). Pengaruh pendidikan kesehatan terhadap pengetahuan, sikap, dan tindakan pencegahan penularan tuberkolosis paru pada keluarga di Kecamatan Sitiung Kabupaten Dhamasraya.

Universitas Andalas (2012). Pedoman penulisan skripsi fakultas keperawatan.

Vivi. (2013). Pengaruh pendidikan kesehatan terhadap pengetahuan dan pelaksanaan rentang gerak sendi aktif post orif pada pasien fraktur ektermitas di M. Djamil Padang

Yuliarti, N. (2010). Panduan lengkap olahraga bagi wanita hamil dan menyusui. Yogyakarta: PT. Andi Offset

Yuswanto \& Yuslifah. (2008). Senam nifas tehadap involusi uterus pada ibu nifas. Diakses tanggal 28 januari 2013 http://jurnal.pdii.lipi.go.id/admin/jurna 1/6208113118_1693-4903.pdf

Yusuf. (2002). Psikologi umum untuk pendidik. Bandung: Pustaka Setia. 